\title{
Dosimetry Evaluation of In-Core and Above-Core Zirconium Alloy Samples in a PWR
}

\author{
Benjamin W. Amiri ${ }^{1}$, John P. Foster ${ }^{2}$, and Larry R. Greenwood ${ }^{3}$ \\ ${ }^{1}$ Westinghouse Electric Company LLC, Radiation Engineering \& Analysis, Cranberry Township, \\ PA 16066, USA \\ ${ }^{2}$ Westinghouse Electric Company LLC, Nuclear Fuel, Hopkins, SC 29061, USA \\ ${ }^{3}$ Battelle Pacific Northwest National Laboratory, Richland, WA 99352, USA
}

\begin{abstract}
A description of the neutron fluence analysis of activated zirconium alloys samples at a Westinghouse 3-loop reactor is presented. These samples were irradiated in the core and in the fuel plenum region, where dosimetry measurements are relatively rare compared with regions radially outward of the core. Dosimetry measurements performed by Batelle/PNNL are compared to the calculational models. Good agreement is shown with the in-core measurements when using analysis conditions expected to best represent this region, such as an assembly-specific axial power distribution. However, the use of these conditions to evaluate dosimetry in the fuel plenum region can lead to significant underestimation of the fluence. The use of a flat axial power distribution, however, does not underestimate the fluence in the fuel plenum region.
\end{abstract}

\section{Introduction}

Westinghouse has developed an improved version of ZIRLO ${ }^{\circledR}$ cladding called Optimized ZIRLO ${ }^{\mathrm{TM}}$ cladding. As part of the testing program for this material, yield strength and ultimate tensile strength of both ZIRLO cladding and Optimized ZIRLO cladding were evaluated as a function of irradiation [1]. Because of the irradiation dependence of the material properties, it was important to accurately characterize the fast fluence experienced by the testing samples.

These samples were irradiated in the core, and above the core in the plenum region, then subjected to post-irradiation examination and materials testing. Because of the importance of accurately determining the fluence experienced by the samples for characterizing irradiation dependence of the material properties, dosimetry analysis of the activated samples was performed. Traditional dosimetry is typically installed in locations radially outward from the core, in the form of surveillance capsules or ex-vessel neutron dosimetry. This program presents a unique opportunity to evaluate the accuracy of the neutron transport methods used for vessel fluence evaluation when applied to the in-core and above-core regions.

*Optimized ZIRLO ${ }^{\mathrm{TM}}$ is a trademark of Westinghouse Electric Company, LLC.

$*$ ZIRLO ${ }^{\circledR}$ is a registered trademark of Westinghouse Electric Company, LLC.

* RadTrack $^{\mathrm{TM}}$ is a trademark of Westinghouse Electric Company, LLC. 


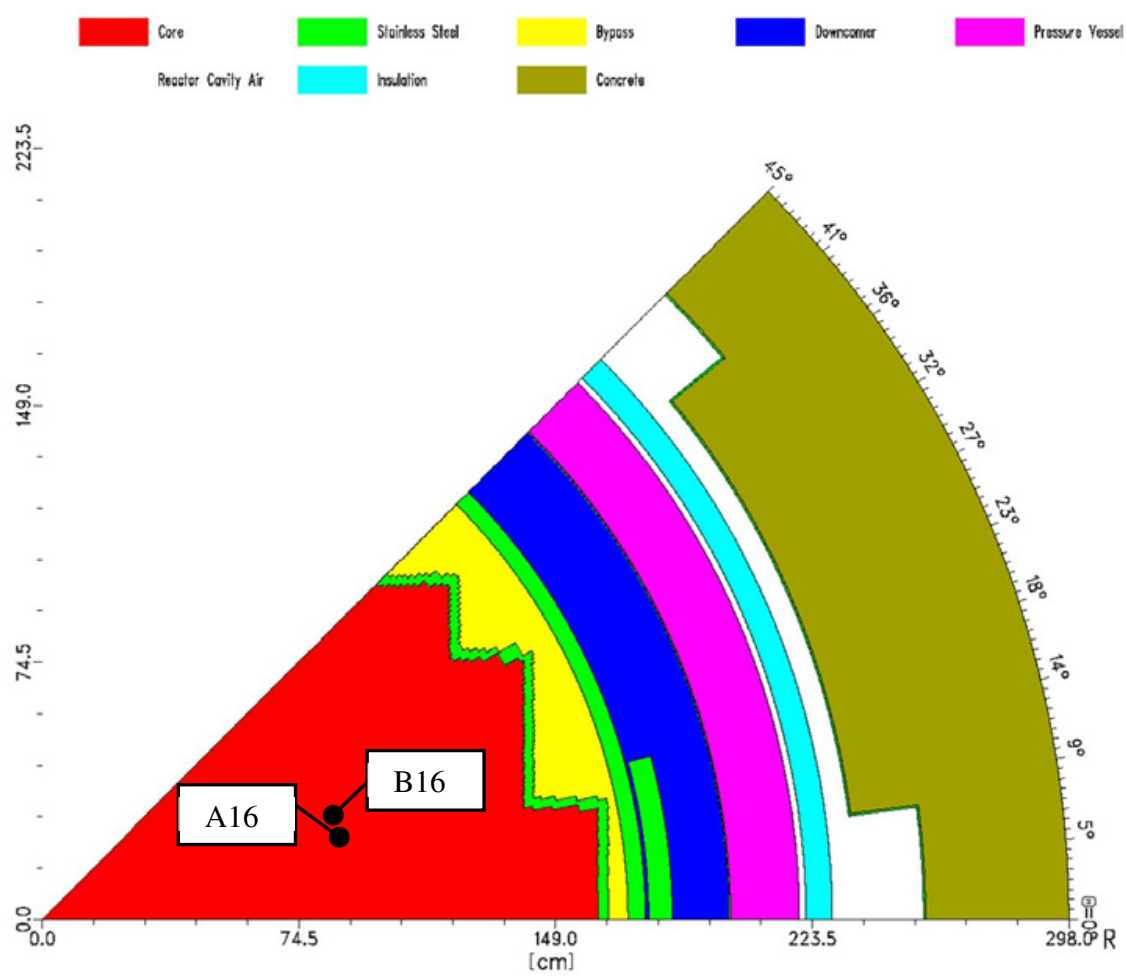

Figure 1. $[\mathrm{r}, \theta]$ model of the 3-loop reactor.

\section{Calculation and Measurement}

Neutron transport calculations were performed with the RadTrack ${ }^{\mathrm{TM}}$ code system [2]. The RadTrack software used the 3D flux synthesis method described in U.S. Nuclear Regulatory Commission Regulatory Guide 1.190 [3]. A plant- and cycle-specific library of flux data was constructed within the RadTrack software using radial and axial power distributions, fuel design specifications, system pressure, and temperatures. The geometric model upon which the transport model is based in represented in Figs. 1 and 2. The broad-group cross section library is based on BUGLE-96 [4]. The flux library obtained by synthesizing DORT [r], $[\mathrm{r}, \theta]$ and $[\mathrm{r}, \mathrm{z}]$ solutions [5] is interrogated by the RadTrack software to obtain the accrued fluence at locations of interest within the reactor geometry.

Several sensitivity cases of neutron transport calculations were run, assessing the effect of coolant temperature and axial power distribution used. Three such cases have been chosen for inclusion here Case B, Case D, and Case F. In Cases B and F, the coolant temperature used when determining the homogenized material density and composition of the core region (as shown in Figs. 1 and 2) was based on the average coolant temperature of peripheral fuel assemblies. This temperature specification is typical of vessel fluence calculations. In Case D, the coolant temperature used when determining the homogenized material density and composition of the core region was based on the upper plenum coolant temperature. The intention of this specification is to more accurately approximate the conditions at axial levels R3, R4, and R5 (as shown in Fig. 2).

The axial power distribution used as input is typically not provided over the entire length of the fuel rod, but rather at discrete points along the rod, the furthest of which is often several centimeters from the axial end of the fuel rod. Extrapolation from the provided power distribution must be employed to 


\section{$15^{\text {th }}$ ISRD}

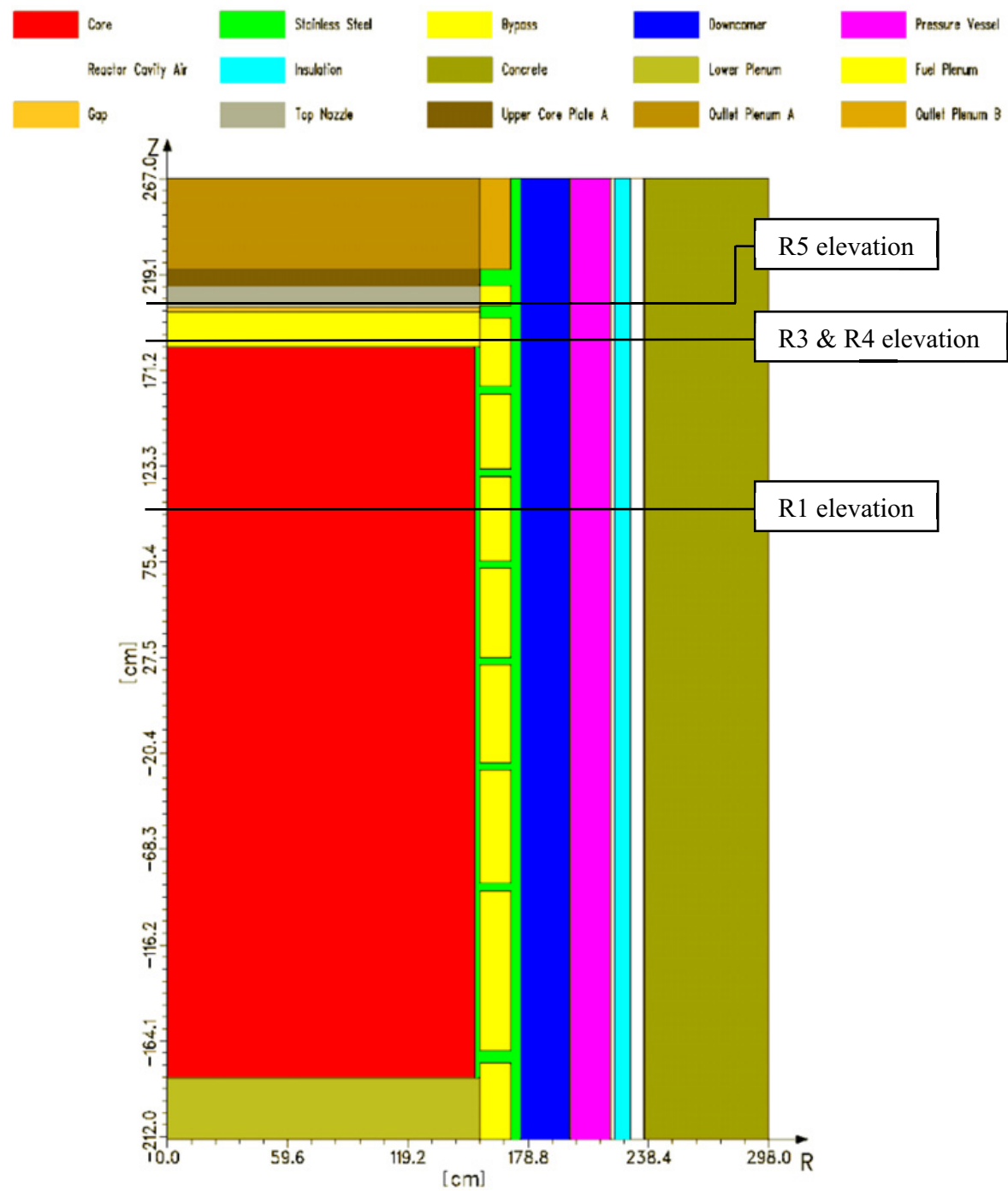

Figure 2. [r,z] model of the 3-loop reactor.

simulate power generation over the entire axial core length. Case B is based on the assembly-average axial power distribution, with linear extrapolation to the axial end of the core. Case D is based on the assembly-average axial power distribution, with extrapolation based on a constant value. Case F uses a uniform axial power distribution over the entire axial length of the core. The assembly-average axial power distribution would be expected to accurately predict the R1 level. The uniform axial power distribution is typically used when assessing exposure of components above and below the core. The axial power distributions used are shown in Fig. 3. A summary of the conditions used for the three cases is given in Table 1.

Dosimetry isotope activation measurements were performed by Battelle/PNNL on six test samples using methods similar to those reported in [6]. For both the Optimized ZIRLO rod (denoted as A16) and the ZIRLO rod (denoted as B16), one sample was located in the fuel region (elevation R1), while 

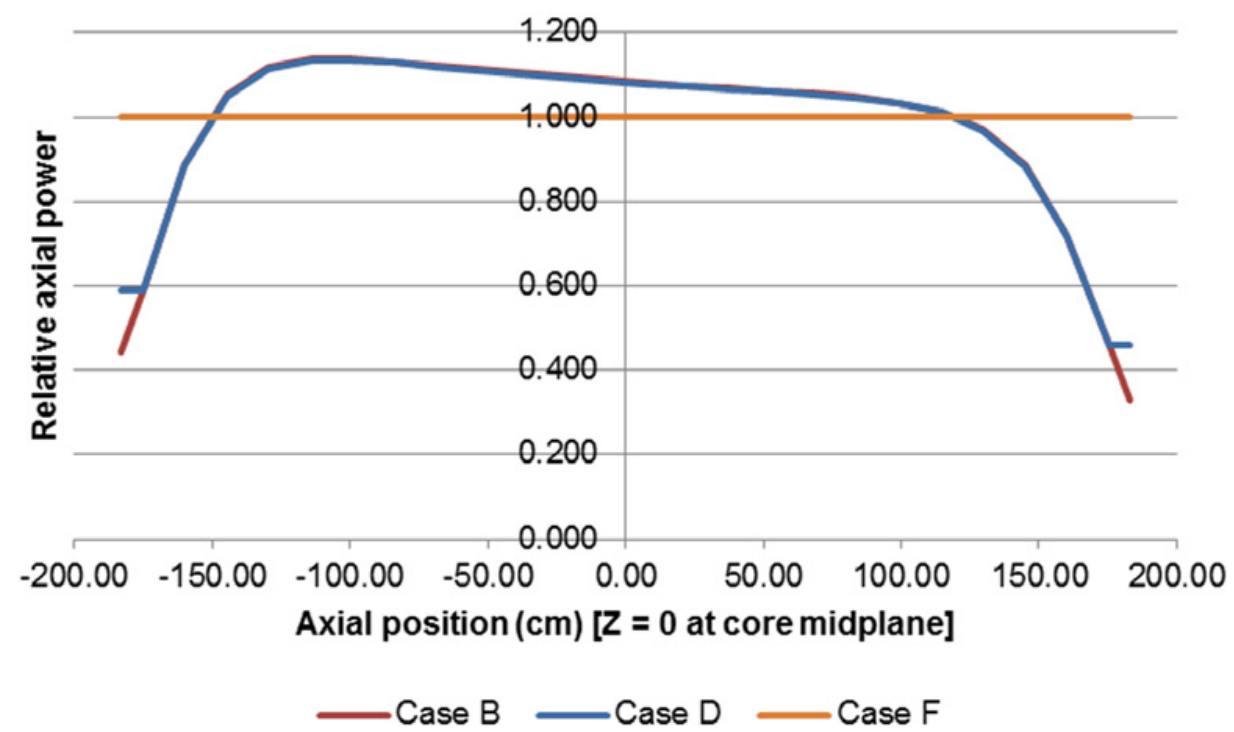

Figure 3. Axial power distributions used in calculated cases.

Table 1. Summary of analysis conditions for calculated cases.

\begin{tabular}{|c|c|c|c|}
\hline \multirow{2}{*}{ Case } & \multicolumn{2}{|c|}{ Axial Power Distribution } & \multirow{2}{*}{ Core Region Temperature } \\
\cline { 2 - 3 } & Basis & Extrapolation & \\
\hline B & Assembly-average & Linear & Peripheral fuel assemblies \\
\hline D & Assembly-average & Constant & Fuel plenum \\
\hline F & Uniform flat & Uniform flat & Peripheral fuel assemblies \\
\hline
\end{tabular}

two samples were located in the plenum region (elevations R3, R4, and R5). The radial and azimuthal sampled rod locations are shown in Fig. 1, while the sampled axial elevations are shown in Fig. 2.

A least-squares adjustment method [7] combining measurement data with the corresponding neutron transport calculations was used to establish a best-estimate spectrum and an estimate of the applicable uncertainties at the locations of measurement. Dosimetry evaluations were performed using SNLRML [8] dosimetry cross-section data at the locations of interest.

Measurement-to-calculation (M/C) reaction rate comparisons based on individual sensor reaction rates without recourse to the least-squares adjustment procedure are summarized in Table 2. Based on the ${ }^{93} \mathrm{Nb}\left(\mathrm{n}, \mathrm{n}^{\prime}\right)^{93 \mathrm{~m}} \mathrm{Nb}$ reaction comparison in Table 2, the Case B calculation represents the in-core (R1) measurements well (M/C of 0.99 and 1.06), but underestimates the fuel plenum measurements (M/C ranging from 1.86 to 2.13). A similar trend is observed for the ${ }^{54} \mathrm{Fe}(\mathrm{n}, \mathrm{p})^{54} \mathrm{Mn}$ reaction.

Measurement-to-best-estimate reaction rate comparisons incorporating the least-squares adjustment are summarized in Table 3. Fluctuations in this table are small compared to those in Table 2. Again considering the ${ }^{93} \mathrm{Nb}\left(\mathrm{n}, \mathrm{n}^{\prime}\right)^{93 \mathrm{~m}} \mathrm{Nb}$ reaction comparison, for Sample A16-R1, the M/BE ratio is 1.04 and is consistent for Case B, Case D, and Case F. The agreement and consistency shown in Table 3 as compared with Table 2 indicates that the best-estimate reaction rates are weighted toward the measured values, and are not particularly sensitive to the spectral differences between Cases B, Case D, and Case F.

This insensitivity of the best-estimate results to the particular calculational case used is further shown in Table 4. In this table, best-estimate fast fluence $(\mathrm{E}>1.0 \mathrm{MeV})$ experienced by each sample is presented. For several samples, the best-estimate fluence does not vary to the significant figures reported 
Table 2. Measured to calculated (M/C) reaction rate comparisons.

\begin{tabular}{|c|c|c|c|c|c|c|}
\hline \multirow{2}{*}{ Sample } & \multicolumn{3}{|c|}{${ }^{54} \mathbf{F e}(\mathbf{n}, \mathbf{p})^{\mathbf{5 4}} \mathbf{M n}$} & \multicolumn{3}{c|}{${ }^{\mathbf{9 3}} \mathbf{N b}\left(\mathbf{n}, \mathbf{n}^{\mathbf{1}}\right)^{\mathbf{9 3 m}} \mathbf{N b}$} \\
\cline { 2 - 7 } & Case B & Case D & Case F & Case B & Case D & Case F \\
\hline A16-R1 & 0.89 & 0.84 & 0.91 & 1.06 & 1.00 & 1.09 \\
\hline A16-R4 & 1.61 & 1.33 & 0.69 & 2.07 & 1.70 & 0.89 \\
\hline A16-R5 & 2.00 & 1.70 & 0.91 & 2.13 & 1.79 & 0.96 \\
\hline B16-R1 & 0.86 & 0.82 & 0.89 & 0.99 & 0.93 & 1.02 \\
\hline B16-R3 & 1.89 & 1.59 & 0.84 & 1.86 & 1.55 & 0.81 \\
\hline B16-R5 & 2.02 & 1.72 & 0.93 & 2.12 & 1.79 & 0.95 \\
\hline
\end{tabular}

Table 3. Measured to best estimate $(\mathrm{M} / \mathrm{BE})$ reaction rate comparisons.

\begin{tabular}{|c|c|c|c|c|c|c|}
\hline \multirow{2}{*}{ Sample } & \multicolumn{3}{|c|}{${ }^{54} \mathbf{F e}(\mathbf{n}, \mathbf{p})^{\mathbf{5 4}} \mathbf{M n}$} & \multicolumn{3}{c|}{${ }^{\mathbf{9 3}} \mathbf{N b}\left(\mathbf{n}, \mathbf{n}^{\prime}\right)^{\mathbf{9 3 m}} \mathbf{N b}$} \\
\cline { 2 - 7 } & Case B & Case D & Case F & Case B & Case D & Case F \\
\hline A16-R1 & 0.95 & 0.95 & 0.95 & 1.04 & 1.04 & 1.04 \\
\hline A16-R4 & 0.95 & 0.95 & 0.93 & 1.09 & 1.08 & 1.05 \\
\hline A16-R5 & 1.00 & 1.00 & 1.00 & 1.04 & 1.03 & 1.01 \\
\hline B16-R1 & 0.96 & 0.96 & 0.99 & 1.03 & 1.03 & 1.03 \\
\hline B16-R3 & 1.02 & 1.02 & 1.00 & 1.02 & 1.01 & 0.99 \\
\hline B16-R5 & 1.01 & 1.01 & 0.99 & 1.03 & 1.03 & 1.01 \\
\hline
\end{tabular}

Table 4. Fast fluence $(\mathrm{E}>1.0 \mathrm{MeV})$ and best estimate to calculated (BE/C) fast fluence comparisons.

\begin{tabular}{|c|c|c|c|c|c|c|}
\hline \multirow[b]{2}{*}{ Sample } & \multicolumn{3}{|c|}{ Fast fluence $\left[\mathbf{n} / \mathrm{cm}^{2}\right]$} & \multicolumn{3}{|c|}{ BE/C } \\
\hline & Case B & Case D & Case $\mathbf{F}$ & Case B & Case D & Case $\mathbf{F}$ \\
\hline A16-R1 & $4.5 e+21$ & $4.5 e+21$ & $4.5 e+21$ & 0.99 & 0.93 & 1.02 \\
\hline A16-R4 & $1.3 e+21$ & $1.3 e+21$ & $1.4 \mathrm{e}+21$ & 1.82 & 1.52 & 0.81 \\
\hline A16-R5 & $2.4 \mathrm{e}+20$ & $2.5 \mathrm{e}+20$ & $2.5 \mathrm{e}+20$ & 2.00 & 1.71 & 0.94 \\
\hline B16-R1 & $4.4 e+21$ & $4.4 e+21$ & $4.4 e+21$ & 0.94 & 0.89 & 0.97 \\
\hline B16-R3 & $8.3 e+20$ & $8.4 \mathrm{e}+20$ & $8.7 e+20$ & 1.81 & 1.52 & 0.82 \\
\hline B16-R5 & $2.1 \mathrm{e}+20$ & $2.1 \mathrm{e}+20$ & $2.2 \mathrm{e}+20$ & 2.00 & 1.71 & 0.94 \\
\hline
\end{tabular}

when using Case B, Case D, or Case F. The largest difference is seen in Sample B16-R3, which varies between $8.3 \mathrm{e}+20$ and $8.7 \mathrm{e}+20 \mathrm{n} / \mathrm{cm}^{2}$, a difference of less than $5 \%$.

Table 4 also shows the relative effectiveness of the computational cases at predicting the final, bestestimate fluence for each sample. As expected, Case B shows good agreement with the in-core samples (R1) of 0.99 and 0.94. Case B, however, underpredicts the fluence of samples in the plenum region (R3, $\mathrm{R} 4, \mathrm{R} 5$ ) by up to a factor of 2 . This is largely attributed to the use of the assembly-average axial power distribution. Case D also uses the assembly-average axial power distribution, but employs material compositions based on fuel plenum temperatures. The result of using the fuel plenum temperatures is slightly better agreement with samples in the plenum region; however the underestimation can still be as high as a factor of 1.71 . When analyzing regions directly above and below the core, a common practice has been to employ core temperatures and a flat axial power distribution, as in Case F. Case F shows better agreement with samples in the plenum region; most importantly, however, best-estimate fluences in the plenum region are not underestimated when using the flat axial power distribution.

\section{Conclusions}

The use of cycle-specific axial power distributions is appropriate for in-core fluence predictions. However, for regions above the core, the use of core-averaged, cycle-specific axial power distributions can lead to significant underestimation of the fluence when using the synthesis method. Future work includes performing a similar evaluation using a full three-dimensional transport evaluation to determine the validity of this conclusion for three-dimensional calculations as well. 
Most dosimetry is installed in areas radially outward from the core in the form of surveillance capsules or ex-vessel neutron dosimetry. These areas are typically of interest from a standpoint of materials degradation due to radiation exposure. However, as plants age, there may be an interest in accurately characterizing the regions above and below the core; for instance, to assess helium generation and subsequent embrittlement in reactor internals, or to calculate activation profiles for decommissioning. More dosimetry data in these regions would allow further refinement of the calculational models and provide guidance as to the most appropriate conditions to consider when modeling these regions of the reactor.

\section{References}

[1] J.P. Foster, A. Muñoz, B.W. Amiri, C. Muñoz-Reja, A. Atwood, "Zirconium Alloy Irradiation Hardening: Yield and Ultimate Strength Comparison of Optimized Zirlo ${ }^{\mathrm{TM}}$ and Zirlo ${ }^{\circledR}$," LWR Fuel Performance Meeting TopFuel (2013)

[2] G.A. Fischer, "RadTrack: An Automated Tool for Tracking the Radiation Environment in LWRs, Version 1.1,"WCAP-16558-NP, Revision 1, Westinghouse Electric Company, Cranberry Township, PA, 2008

[3] U.S. Nuclear Regulatory Commission Regulatory Guide 1.190, "Calculational and Dosimetry Methods for Determining Pressure Vessel Neutron Fluence," U.S. Government Printing Office, Washington, DC, 2001

[4] RSICC Data Library Collection DLC-185, "BUGLE-96, Coupled 47 Neutron, 20 Gamma-Ray Group Cross Section Library Derived from ENDF/B-VI for LWR Shielding and Pressure Vessel Dosimetry Applications," Radiation Safety Information Computational Center, Oak Ridge, TN, 1996

[5] RSICC Computer Code Collection CCC-650, "DOORS 3.2, One-, Two-, and Three-Dimensional Discrete Ordinate Neutron/Photon Transport Code System," Radiation Safety Information Computational Center, Oak Ridge, TN, 1998

[6] L.R. Greenwood and J.P. Foster, "Retrospective Reactor Dosimetry with Zirconium Alloy Samples in a PWR," Proceedings of the $13^{\text {th }}$ International Symposium on Reactor Dosimetry pp. 58-66 (2008)

[7] S.L. Anderson, "Benchmark Testing of the FERRET Code for Least Squares Evaluation of Light Water Reactor Dosimetry," WCAP-16083-NP-A, Revision 0, Westinghouse Electric Company, Cranberry Township, PA, 2006

[8] RSICC Computer Code Collection DLC-178, "SNLRML, Recommended Dosimetry CrossSection Compendium,” Radiation Safety Information Computational Center, Oak Ridge, TN, 1994 